\title{
Two Types of Growth: How Does Structural Transformation Lead to Steady Economic Development?
}

\author{
Fumihide Takeuchi
}

Department of Economics, School of Political Science and Economics, Tokai University, 4-1-1 Kitakaname, Hiratsuka-shi, Kanagawa 259-1292, Japan

DOI: $10.36348 /$ sjef.2020.v04i01.006 | Received: 13.01 .2020 | Accepted: 21.01 .2020 | Published: 24.01 .2020

*Corresponding author: Fumihide Takeuchi

\section{Abstract}

This paper examines structural transformation mechanisms in developing countries, focusing on the shift from highproductivity, tradable sectors (agriculture and manufacturing) to low-productivity, service sectors and assesses how these elements contribute to rising income levels. Different relationships exist between countries' structural transformations and economic development. The first group of countries shows sluggish income growth and rapid growth in services, and the second group of countries shows a more gradual shift to services, resulting in higher economic growth. With a simple, static model, with sector-specific distortion that replicates the actual, two-sector, relative TFP, capital stock and capital share well, we find a gradual increase in capital intensification in the tradable sector, coupled with a gradual shift to services (in line with comparative advantages) is the most important cause of sustained economic growth.

Keywords: Structural transformation; share of services; relative price effects; capital intensity; capital deepening; total factor productivity.

Copyright @ 2020: This is an open-access article distributed under the terms of the Creative Commons Attribution license which permits unrestricted use, distribution, and reproduction in any medium for non-commercial use (NonCommercial, or CC-BY-NC) provided the original author and source are credited.

JEL Classification: O14; O41

\section{INTRODUCTION}

Structural transformation of countries whose economic focus shifts from agriculture and manufacturing to services is a worldwide phenomenon. Theoretical and empirical studies have explored the mechanisms behind this structural transformation and their impact on macro economies. This paper specifically deals with the second topic, emphasizing empirically observable relationships between structural transformation and income growth. Regarding the former, we focus on the relationship between the tradable and services sectors, because the latter historically grows more rapidly with economic development. However, because productivity in the services sector is relatively low, proportional increases in this sector can slow a country's overall growth rate. In this respect, a move to services has an important effect on a country's economic development $\left[{ }^{1}\right]$.

\footnotetext{
${ }^{1}$ Productivity data shows substantial differences in the growth rates of TFP (Total Factor Productivity) across sectors. TFP in tradable sectors (especially in agriculture) rose strongly, while TFP in services showed weak growth (see Herrendorf et al., [1]).
}

Figure-1 shows the relationship between the services sector's share of nominal value-added (the vertical axis, a percentage) and GDP per-capita (the horizontal axis, a logarithmic value) from 1950 to 2013 for high-income OECD countries, including Taiwan. On the far left of Figure-1, the services sector's share in Japan, South Korea and Taiwan is mostly constant, and per-capita income grows at a steady rate from the outset. On the other hand, at a later stage, services' overall share in the economy moves upwards, but its growth rate declines. Major differences appear, though, if developing countries are added to the analysis. The more dispersed shares of services in countries with lower income levels are shown in Figure-2. According to this figure, developing countries (excluding East Asia, but including those in Latin America), show sluggish income growth but rapid growth of services. By contrast, the shift to services has been more gradual in many East Asian countries, resulting in higher 
economic growth. With GDP per-capita on the horizontal axis and services' share on the vertical axis, the transformations shown in the figure are less pronounced for East Asia but relatively steep for Latin America.

This study's purpose is to identify structural transformation mechanisms in developing countries and assess how these mechanisms contribute to rising income levels. In particular, we look at how economic growth in East Asian countries (typically high-growth countries gradually shifting to services) differs from that in other developing countries (low-growth countries also rapidly shifting to services). A further purpose of this study is to assess whether this mechanism differs between developing and developed countries.
These questions are particularly important when we consider future Chinese economic trends. After the worldwide 2009 recession, attention has focused on structural transformations related to lower economic growth in China. In this country, the proportion of services has grown dramatically, from $44.3 \%$ of the total economy in 2011 to $52.2 \%$ in 2018 on a value-added basis and from $37.1 \%$ to $44.6 \%$ when measured by employment share (sources: World Development Indicators, the World Bank). As the country's exports slow down, the Chinese government hopes the services sector will pick up the slack in employment, even though rapid increases in this sector could dampen income growth nationwide. A shift towards services at this pace in the Chinese economy would further constrain economic development, making the transformation from a mid-income to a high-income country more difficult.

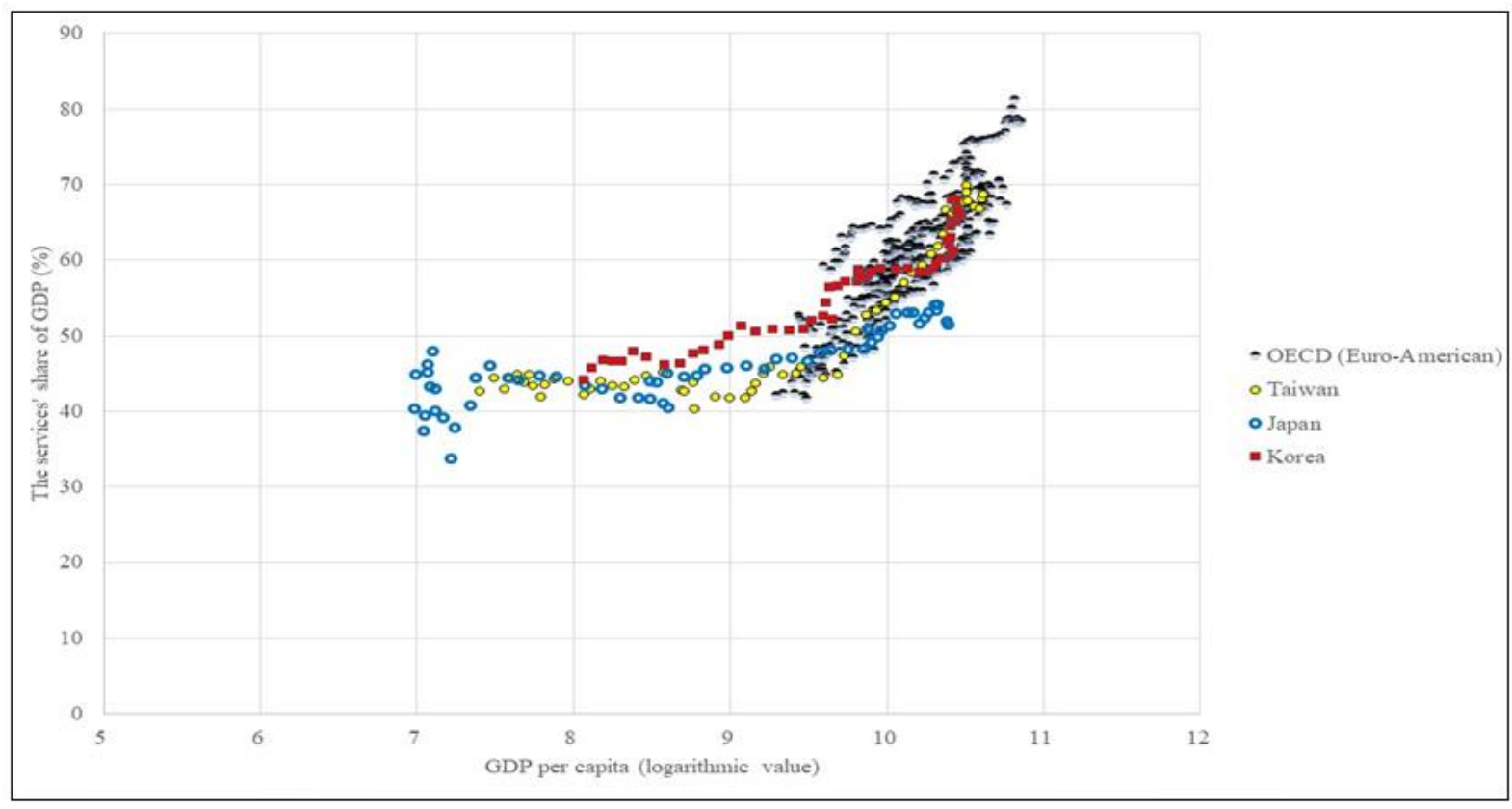

Fig-1: The Service Sector's Share of Nominal Value-Added and GDP Per-Capita.

Notes: This figure shows the relationship for Japan, South Korea and Taiwan and the following Euro-American OECD countries: the U.S., Germany, Denmark, Spain, France, the United Kingdom, Italy, the Netherlands and Sweden from 1950 to 2013. (The data was obtained from The Groningen Growth and Development Centre's Ten-Sector Database).

As summarised by Herrendorf et al., [1], who conducted a comprehensive survey of prior research in this field, structural transformation is largely driven by demand-side factors (income effects) and supply-side factors (relative price effects). Income effects focus on the low income elasticity of demand for agricultural products and the diminishing percentage of agricultural products in a country's overall consumption as residents' incomes rise. Relative price effects focus on the lower level of labour productivity in the services sector versus the tradable sector. Labour productivity in these two sectors is affected by relative total factor productivity (TFP) and relative capital deepening (capital stock per unit of labour). If the elasticity of substitution between the consumption of tradable goods and services is below one (assuming a complementary relationship between tradable goods' and services' consumption), the services sector's lower productivity increases the services sector's share of nominal added value. In this case, TFP also shifts production from highly productive sectors to unproductive ones, which are primarily supply-side issues. If productivity in the services sector is lower than in the tradable sector, a larger services sector can harm overall output growth. 


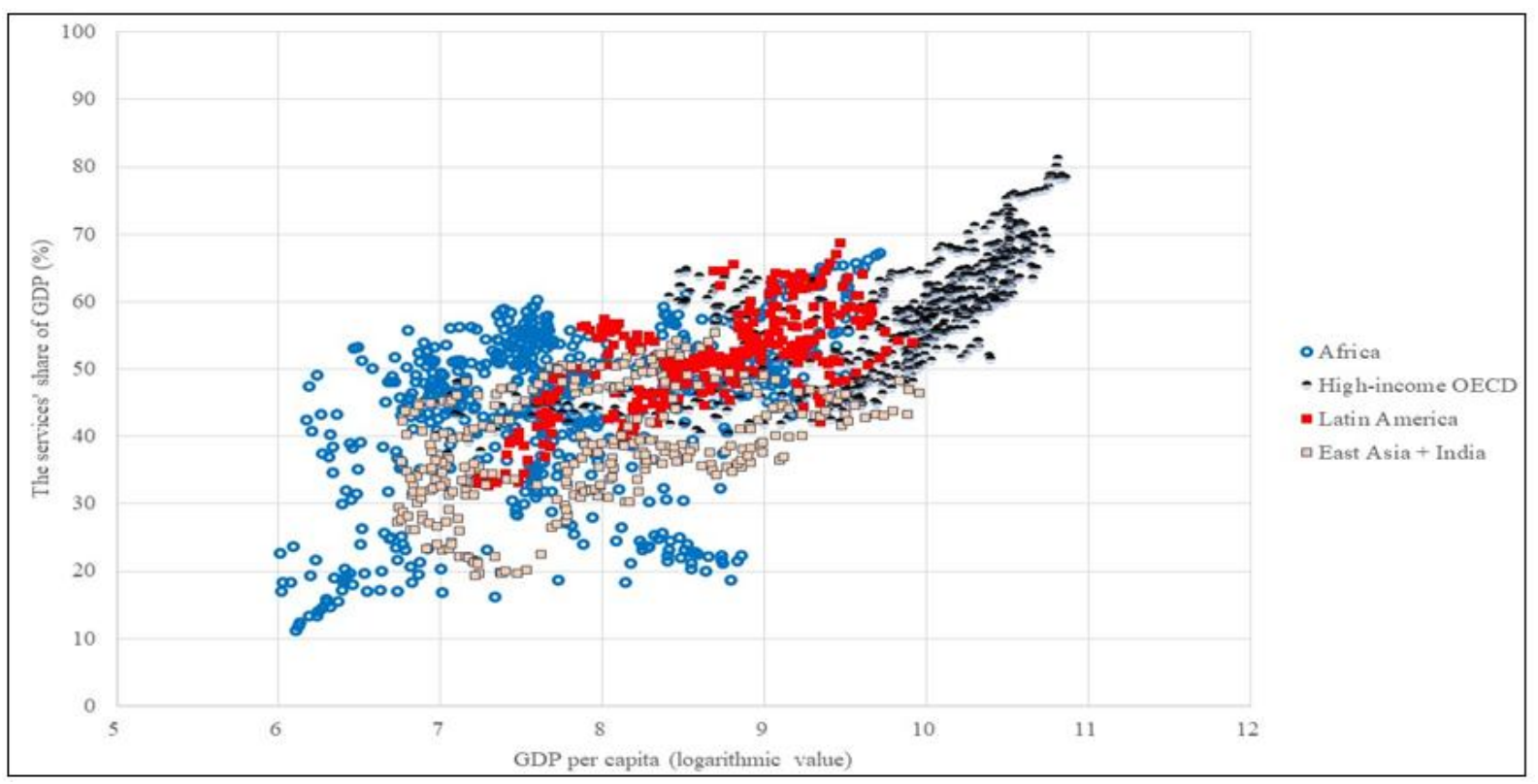

Fig-2: The Service Sector's Share of Nominal Value-Added and GDP Per-Capita

Notes: This Figure shows the relationship for 38 countries, divided into four groups: 1. Africa (Botswana, Ethiopia, Ghana, Kenya, Malawi, Mauritius, Nigeria, Senegal, South Africa, Tanzania, Zambia, Egypt and Morocco); 2. East Asia and India (China, India, Indonesia, Malaysia, the Philippines and Thailand); 3. Latin America (Argentina, Bolivia, Brazil, Colombia, Costa Rica and Mexico) and 4. high-income OECD countries plus Taiwan (the U.S., Germany, Denmark, Spain, France, the United Kingdom, Italy, the Netherlands, Sweden, Japan, South Korea, Taiwan and Chile) from 1950 to 2013. (Sources: The Groningen Growth and Development Centre's 10-Sector Database). The term 'high-income' is based on the World Bank's definition.

This study uses a static growth model that focuses solely on optimal demand (consumption) and supply conditions within each period and carries out a factor decomposition analysis of industrial structure changes from the tradable sector to the services sector. For developed countries, labour and capital compensation and capital stock data by industry are available. Significant data constraints, however, exist for developing countries. Using GDP, GDP deflators and employment data for each industry, this model allows us to calculate labour and capital shares analytically for the two sectors, as well as their relative capital deepening and relative TFP. We review the model's effectiveness by comparing the actual data with our calculations.

The analytical results show it is important for developing economies to gradually increase the degree of capital deepening (capital intensity) in the tradable sector, in line with its comparative advantage (an abundant labour force). Capital intensity, which is gradually increasing in East Asia's tradable sector, emphasizes a tradable-sector-oriented, industrial structure that contributes to higher macro-level income. At the same time, relative TFP for the tradable sector, versus the services sector, is rising in East Asian developing countries. This raises the relative prices of services, increases the services sector's nominal valueadded share and simultaneously contributes to a rise in income. The combined effect of gradual capital intensification and higher relative TFP increases services' share of nominal added value which rises gradually and causes a relatively large rise in income. This is consistent pattern of development in East Asia. In other developing regions, rapid growth in capital intensification in the tradable sector indicates rapid growth of services. Rapid capital intensification in the tradable sector, contrary to its comparative advantage, suppresses income growth.

This paper's contributions can be summarised as follows. First, as already explained, although the literature empirically explores the connection between structural transformation and overall economic growth, previous studies have not focused on the distinctly different relationship between industrial structure and economic development (a gradual shift to services and high growth, versus a rapid shift to services and low growth). This lacunae is surprising. Second, this paper newly interprets economic growth mechanisms in East Asia from the perspective of structural transformation and growth accounting. This study verifies that the development of labour-intensive industries abets stable economic growth if a gradual structural transformation uses comparative advantages during its initial phases. Within a growth accounting framework, one open question is whether TFP or an accumulation of production factors is the more important driver of economic growth in East Asia. In contrast to Krugman [2], who argued that accumulation of production factors 
(not productivity) created high growth in East Asia, Jorgenson and $\mathrm{Vu}$ [3] concluded, based on data from the World Bank's International Comparison Program (ICP), that productivity increases underpinned the 'East Asian Miracle' until the mid-1990s. They added that this productivity later shifted to growth, which depended on accumulating production factors. This paper's analysis, which focuses on changes in the labour and capital intensities of different sectors, reveals that developing countries need to raise gradually the relative capital intensity of tradable sectors (agriculture and manufacturing) because of their comparative advantages, compared to those of the services sector. This paper introduces a new perspective on these prior studies.

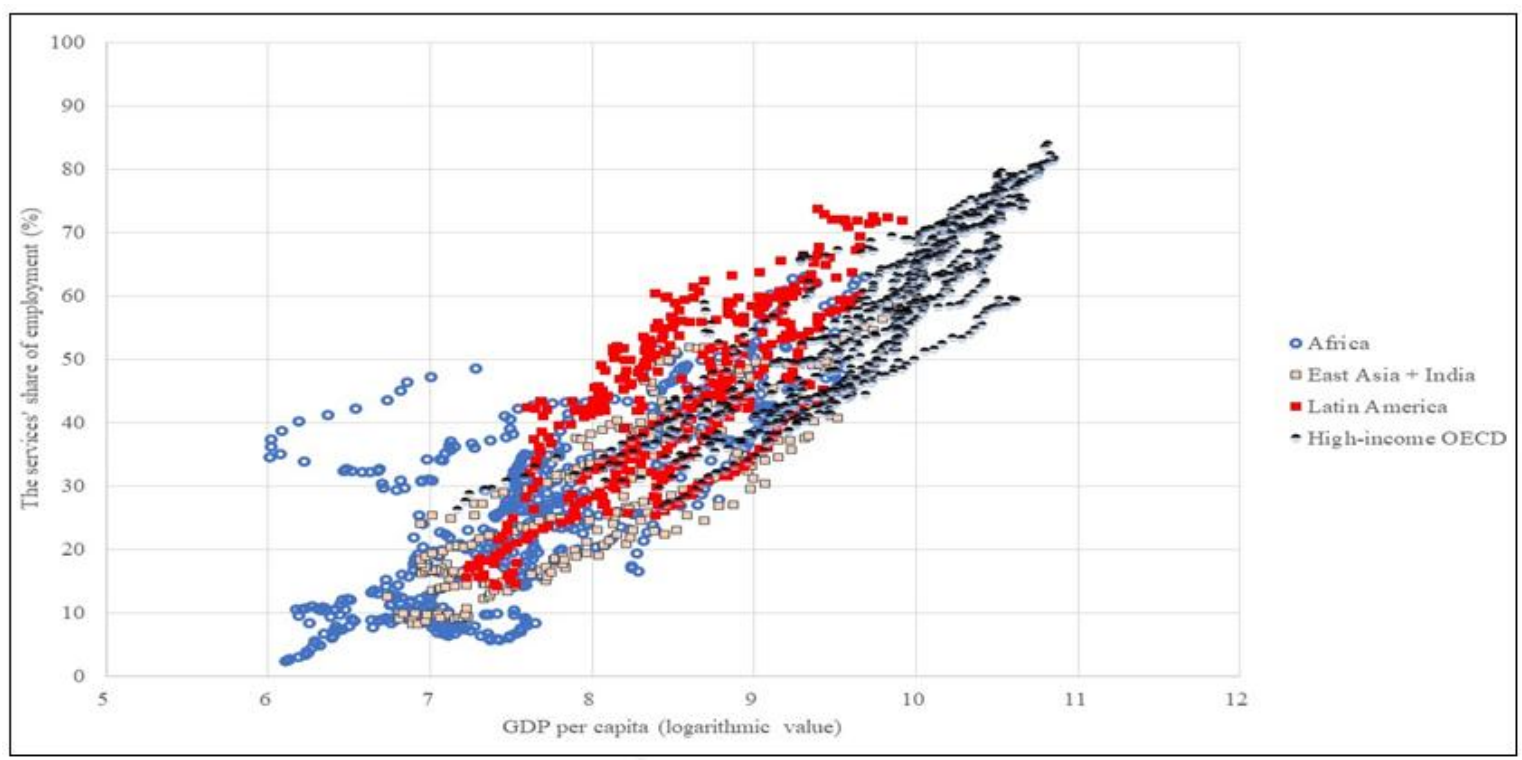

Fig-3: The Service Sector's Share of Employment and GDP Per-Capita

Notes: This figure shows the relationship, from 1950 to 2013, for 39 countries (all 38 countries sampled in Figure-3, plus Peru). (Source: The Groningen Growth and Development Centre's Ten-Sector Database).

Third, by simultaneously analysing the shares of value-added and employment, this paper focuses on the important observed fact of structural transformation, which is that the services sector's share of employment increases at a higher rate than the sector's added value. Previous studies on structural transformation have little explored these differing structural transformation patterns. Different rates of change in value-added and employment shares indicate stagnant per-capita income in the services sector, which could lead to personal income inequality $\left[^{2}\right]$. Distribution of social income has been a topic of increasing interest in recent years. Figure-3 shows changes in the services sector's share of employment for all countries sampled in Figure-2. Compared with Figure-2, which shows the services sector's GDP share, Figure-2 indicates that the services sector's share of employment grows at a mostly consistent and more rapid rate in accordance with income. We also find that the services sector's share of employment grows faster in Latin America than in other global areas. All these differences between growth rates of value added and employment shares and between

${ }^{2}$ See Takeuchi [8].
Latin America and others in employment share growth are related to the changes in capital intensity. Using a similar model, Dennis and İşcan [10], who examined changes in the shares of U.S. agriculture and manufacturing, keep labour and capital intensities constant and only analyse employment shares. Their model did not analyse the differences between shares of production and employment as the service sector grows.

Some previous studies (i.e. Verma [4] and Buera and Kaboski [5]) also focused on structural transformations in developing countries and the differences between value-added and employment shares. Verma [4] analysed why, unlike in other countries, employment share changes in India were smaller than value-added share changes. Based on the seminal works of Kongsamut et al., [6] and Ngai and Pissarides [7], both of which incorporated structural change into a traditional balanced-growth model, Buera and Kaboski [5] opined that this type of model should incorporate sectoral production factor distortions to match actual, long-term U.S. data. As explained in the next chapter, this paper's model includes these types of distortions.

This paper is organised as follows. Chapter 2 outlines the structure of the model, and Chapter 3 summarises the method used for the factor decomposition analysis of industrial structures based on this model. Chapter 4 explains the analytical results and 
notes the impact of structural transformation mechanisms on economic development. Chapter 5 provides an overall summary and a conclusion.

\section{THE MODEL}

\section{Production and Preferences}

To factorise structural transformation, our model focuses solely on the implications of optimal consumption and production behaviour within each period. An advantage of this static approach is that firstorder conditions for stand-in households and firms are provided only by current, observed variables. It is not necessary to take a stand about the exact nature of intertemporal opportunities available to households and firms (i.e. the appropriate interest rates for borrowing and lending). In what follows, subscript $t$, which indicates a time period, is omitted in each variable.

The model has two activity sectors, the tradable sector $(T)$ and the services sector $(S)\left[^{3}\right]$. The tradable sector includes agriculture and manufacturing, and the production function in each sector is assumed to be Cobb-Douglas, with constant returns to scale. A static approach allows all variables to change in each period, with no exceptions. Capital share $\left(\theta_{T}, \theta_{S}\right)$ is also assumed to change in each period. The output of services can be used for consumption $\left(C_{S}\right)$ and investment $\left(I_{S}\right)$. The tradable sector's output can be disaggregated into consumption $\left(C_{T}\right)$, investment $\left(I_{T}\right)$ and net exports $\left(N E X_{T}\right)$. Shares of investments and net exports in each sector are exogenously determined in the model. Production structures and their market clearings in product markets are as follows:

$$
\begin{aligned}
Y_{S} & =A_{S} K_{S}^{\theta_{S}} L_{S}^{1-\theta_{S}}=C_{S}+I_{S} \\
Y_{T}=A_{T} K_{T}^{\theta_{T}} L_{T}^{1-\theta_{T}} & =C_{T}+I_{T}+N E X_{T}
\end{aligned}
$$

Where $Y_{i}, A_{i}, K_{i}$ and $L_{i}$ are value-added, total factor productivity (TFP), capital stock and employment in $i=T, S$, respectively. All resources for production $\left(K_{i}, L_{i}\right)$ are fully used.

$K_{S}+K_{T}=K$

$L_{S}+L_{T}=L$

We assume that the period utility function $u\left(C_{S}, C_{T}\right)$ is of the form:

$$
u\left(C_{S}, C_{T}\right)=\left[\omega^{\frac{1}{\varepsilon}} C_{S}^{\frac{\varepsilon-1}{\varepsilon}}+(1-\omega)^{\frac{1}{\varepsilon}} C_{T}^{\frac{\varepsilon-1}{\varepsilon}}\right]^{\frac{\varepsilon}{\varepsilon-1}}
$$

Equation (3) is a homothetic CES preference equation that does not take income effects into consideration. The model focuses on relative price effects to detect factors that uncover long-term structural transformations, as described below.

\section{Optimality Conditions}

We now derive production-side efficiency. Perfect factor mobility exists across the two sectors if sector-specific distortions to production factors (capital and employment) are cleared. First-order conditions for a stand-in firm in sector $i$ are given by:

$$
\begin{aligned}
& R=\frac{1}{1+d_{S}} P_{S} \theta_{S} A_{S}\left(\frac{K_{S}}{L_{S}}\right)^{\theta_{S}-1}=\frac{1}{1+d_{T}} P_{T} \theta_{T} A_{T}\left(\frac{K_{T}}{L_{T}}\right)^{\theta_{T}-1} \\
& W=\frac{1}{1+d_{S}} P_{S}\left(1-\theta_{S}\right) A_{S}\left(\frac{K_{S}}{L_{S}}\right)^{\theta_{S}}=\frac{1}{1+d_{T}} P_{T}\left(1-\theta_{T}\right) A_{T}\left(\frac{K_{T}}{L_{T}}\right)^{\theta_{T}}
\end{aligned}
$$

$P_{i}$ is the price of sector $i$, while $R$ and $W$ denote the rental rates of capital and employment, respectively, both of which are expressed in nominal currency. The term $d_{i}\left(d_{i} \geq 0\right)$ denotes a sector-specific distortion. Although Dennis and İșcan [10] did not consider this distortion factor, it is necessary when considering developing economies.

Dividing these two equations by each other gives:

$$
\frac{1-\theta_{S}}{\theta_{S}}\left(\frac{K_{S}}{L_{S}}\right)=\frac{1-\theta_{T}}{\theta_{T}}\left(\frac{K_{T}}{L_{T}}\right)
$$

From the second equation in Equation (4), the implications for relative prices can be derived as

$$
\frac{P_{S}}{P_{T}}=\frac{1-\theta_{T}}{1-\theta_{S}} \frac{A_{T}}{A_{S}} \frac{k_{T}^{\theta_{T}}}{k_{S}^{\theta_{S}}} \frac{1+d_{S}}{1+d_{T}}
$$

In the above equation, $k_{S}=\frac{K_{S}}{L_{S}}, k_{T}=\frac{K_{T}}{L_{T}}$.

Observing the price of services $P_{S}^{C}$ and the price of tradable products $P_{T}^{C}$ for consumption, the firstorder condition for a stand-in households corresponds to:

$$
\left(\frac{P_{S}^{C}}{P_{T}^{C}}\right)^{\varepsilon} \frac{C_{S}}{C_{T}}=\frac{\omega}{1-\omega}
$$

The two consumption prices, $P_{S}^{C}$ and $P_{T}^{C}$, are different from the GDP deflators, $P_{S}$ and $P_{T}$, because the former includes import prices, and the latter does not. The proportion of relative consumption prices to relative GDP deflators, or the exogenous price effect $(\Phi)$, is defined as follows:

$$
\frac{P_{S}^{C}}{P_{T}^{C}}=\Phi \frac{P_{S}}{P_{T}}
$$

\footnotetext{
${ }^{3}$ This paper uses the extended version of the model in Takeuchi [9] which uses the model to obtain the data of labor share and capital stock for the tradable and services sectors. Therefore, the paper described only the model's formulae (1)-(6) mentioned above.
} 
We derive the consumption value of services relative to that of tradable products $\left(\frac{P_{S}^{C} C_{S}}{P_{T}^{C} C_{T}}\right)$ and the sectoral allocation of employment across the two sectors $\left(\frac{L_{S}}{L_{T}}\right)$. From Equations (6), (7) and (8), relative consumption values across the two sectors are obtained as follows:

$$
\frac{P_{S}^{C}}{P_{T}^{C}} \frac{C_{S}}{C_{T}}=\left(\frac{P_{S}^{C}}{P_{T}^{C}}\right)^{1-\varepsilon} \frac{\omega}{1-\omega}=\Phi^{1-\varepsilon}\left(\frac{P_{S}}{P_{T}}\right)^{1-\varepsilon} \frac{\omega}{1-\omega}=\Phi^{1-\varepsilon}\left(\frac{1-\theta_{T}}{1-\theta_{S}}\right)^{1-\varepsilon}\left(\frac{A_{T}}{A_{S}}\right)^{1-\varepsilon}\left(\frac{k_{T}^{\theta_{T}}}{k_{S}{ }_{S}}\right)^{1-\varepsilon}\left(\frac{1+d_{S}}{1+d_{T}}\right)^{1-\varepsilon} \frac{\omega}{1-\omega}
$$

Based on Equation (1), we define the relationship between $Y_{S}$ and $C_{S}$ as $Y_{S}\left(1-\gamma_{S}\right)=C_{S}$. We also define the relationship between $Y_{T}$ and $C_{T}$ as $Y_{T}\left(1-\gamma_{T}-\tau_{T}\right)=C_{T}$, where $\gamma_{S}=\frac{I_{S}}{Y_{S}}, \gamma_{T}=\frac{I_{T}}{Y_{T}}$ and $\tau_{T}=\frac{N E X_{T}}{Y_{T}}$. By using these definitions and Equation (7), Equation (10), the next equation, is derived.

$$
\frac{Y_{S}}{Y_{T}} \frac{1-\gamma_{S}}{1-\gamma_{T}-\tau_{T}}=\frac{C_{S}}{C_{T}}=\left(\frac{P_{S}^{C}}{P_{T}^{C}}\right)^{-\varepsilon} \frac{\omega}{1-\omega}
$$

To derive the implications for relative employment allocation, we substitute Equation (1) into Equation (10) and rearrange, obtaining:

$$
\begin{aligned}
& \frac{A_{S}}{A_{T}} \frac{k_{S}^{\theta_{S}}}{k_{T}^{\theta_{T}}} \frac{L_{S}}{L_{T}}=\left(\frac{P_{S}^{C}}{P_{T}^{C}}\right)^{-\varepsilon} \frac{\omega}{1-\omega} \frac{1-\gamma_{T}-\tau_{T}}{1-\gamma_{S}}=\Phi^{-\varepsilon}\left(\frac{P_{S}}{P_{T}}\right)^{-\varepsilon} \frac{\omega}{1-\omega} \frac{1-\gamma_{T}-\tau_{T}}{1-\gamma_{S}} \\
& =\Phi^{-\varepsilon}\left(\frac{1-\theta_{T}}{1-\theta_{S}}\right)^{-\varepsilon}\left(\frac{A_{T}}{A_{S}}\right)^{-\varepsilon}\left(\frac{k_{T}^{\theta_{T}}}{k_{S}^{\theta_{S}}}\right)^{-\varepsilon}\left(\frac{1+d_{S}}{1+d_{T}}\right)^{-\varepsilon} \frac{\omega}{1-\omega} \frac{1-\gamma_{T}-\tau_{T}}{1-\gamma_{S}} \ldots \ldots \ldots \ldots \ldots . . . \ldots \ldots
\end{aligned}
$$

Equation (11) can be rearranged to obtain the next equation, Equation (12), for relative employment allocation $\left(\frac{L_{S}}{L_{T}}\right)$.

$$
\frac{L_{S}}{L_{T}}=\Phi^{-\varepsilon}\left(\frac{1-\theta_{T}}{1-\theta_{S}}\right)^{-\varepsilon}\left(\frac{A_{T}}{A_{S}}\right)^{1-\varepsilon}\left(\frac{k_{T}^{\theta_{T}}}{k_{S}^{\theta_{S}}}\right)^{1-\varepsilon}\left(\frac{1+d_{S}}{1+d_{T}}\right)^{-\varepsilon} \frac{\omega}{1-\omega} \frac{1-\gamma_{T}-\tau_{T}}{1-\gamma_{S}}
$$

Finally, we obtain factors to determine consumption (value-added) and employment shares of services. From Equation (9), relative consumption for these two sectors is factorised into the following four factors: (1) relative capital deepening $\left(\frac{1-\theta_{T}}{1-\theta_{S}}\right)^{1-\varepsilon}\left(\frac{k_{T}^{\theta_{T}}}{k_{S}^{\theta_{S}}}\right)^{1-\varepsilon} ;$ (2) relative TFP $\left(\frac{A_{T}}{A_{S}}\right)^{1-\varepsilon}$ exogenous price effects $\Phi^{1-\varepsilon}$ and (4) distortion $\left(\frac{1+d_{S}}{1+d_{T}}\right)^{1-\varepsilon}$. From Equation (12), relative employment for the two sectors is determined by the following five factors: (1) relative capital deepening $\left(\frac{1-\theta_{T}}{1-\theta_{S}}\right)^{-\varepsilon}\left(\frac{k_{T}^{\theta_{T}}}{k_{S}^{\theta_{S}}}\right)^{1-\varepsilon}$; (2) relative TFP $\left(\frac{A_{T}}{A_{S}}\right)^{1-\varepsilon}$; (3) exogenous price effects $\Phi^{-\varepsilon}$; (4) distortion $\left(\frac{1+d_{S}}{1+d_{T}}\right)^{-\varepsilon}$ and (5) the composition of demand $\frac{1-\gamma_{T}-\tau_{T}}{1-\gamma_{S}}$.

\section{Factor Decomposition and Data}

Among the several factors determining sectoral transformation in the previous chapter, relative labour share $\left(\frac{1-\theta_{T}}{1-\theta_{S}}\right)$, capital stock's share of services $\left(\frac{K_{S}}{K}\right)$ and relative TFP $\left(\frac{A_{T}}{A_{S}}\right)$ are calculated analytically using the model and basic sectoral data. This approach is taken because sectoral data are not available in many developing countries. We then compare the calculated variables to the actual, available data for developed (and some developing) countries to check the model's usefulness. In this chapter, we discuss the process of calculating the model's factors and data, and we compare these calculated variables to the actual data.

From Equation (6) in the model, relative labour share $\left(\frac{1-\theta_{T}}{1-\theta_{S}}\right)$ (where $\theta_{T}$ and $\theta_{S}$ are the two sectors' respective capital shares) can be calculated by dividing relative price $\left(\frac{P_{S}}{P_{T}}\right)$ by relative labour productivity $\quad\left(\frac{Y_{T}}{L_{T}} / \frac{Y_{S}}{L_{S}}=A_{T}\left(\frac{K_{T}}{L_{T}}\right)^{\theta_{T}} / A_{S}\left(\frac{K_{S}}{L_{S}}\right)^{\theta_{S}} \quad\right)$, assuming that $d_{i}=0$. To obtain relative labour share $\left(\frac{1-\theta_{T}}{1-\theta_{S}}\right)$, the relative price $\left(\frac{P_{S}}{P_{T}}\right)$ should be the absolute relative price.

With macro-economic labour share $\left(\theta_{N}\right)$, the ratio of the tradable sector to total GDP $\left(\alpha_{T}\right)$ and the ratio of the tradable sector to total labour compensation $\left(\beta_{T}\right) \beta_{T}$ is derived as $\beta_{T}=\frac{\theta_{L T}}{\theta_{N}} \alpha_{T}=\frac{\theta_{L S}}{\theta_{N}} \alpha_{T}+(1-$ $\left.\frac{\theta_{L S}}{\theta_{N}}\right) \cdot \alpha_{T}$ then is derived as $\alpha_{T}=\frac{\theta_{N}-\theta_{L S}}{\theta_{L T}-\theta_{L S}}$, where $\theta_{L T}$ and $\theta_{L S}$ represent the labour share of the tradable and services sectors, respectively. Among the variables in the equation $\alpha_{T}=\frac{\theta_{N}-\theta_{L S}}{\theta_{L T}-\theta_{L S}}, \alpha_{T}$ and $\theta_{N}$ are known data. Then, by solving a system of equations involving two variables $\theta_{L T}$ and $\theta_{L S}$, or $\alpha_{T}=\frac{\theta_{N}-\theta_{L S}}{\theta_{L T}-\theta_{L S}}$ and $\frac{\theta_{L T}}{\theta_{L S}}(=$ $\left.\frac{1-\theta_{T}}{1-\theta_{S}}\right)$, the two sectors' labour shares $\left(\theta_{L T}\right.$ and $\left.\theta_{L S}\right)$ are obtained. By substituting these labour shares into Equation (5), the relative capital-labour ratio for the two 
sectors $\left(\frac{K_{T}}{L_{T}} / \frac{K_{S}}{L_{S}}\right)$ can be calculated. The two sectors' employment data $\left(L_{T}\right.$ and $\left.L_{S}\right)$ are available, and the capital ratio $\frac{K_{T}}{K_{S}}$ for the two sectors can be calculated. Using total capital stock data $K\left(K=K_{S}+K_{T}\right)$, the capital stock of sectors $K_{T}$ and $K_{S}$ are obtained. Finally, the relative TFP ratio $\left(\frac{A_{T}}{A_{S}}\right)$ is obtained using Equation (6).

Next, using Equations (7) and (8), we consider each sector's prices and consumption demand. Referring to Equation (1), demand for tradable products is decomposed into consumption $\left(C_{T}\right)$, investment $\left(I_{T}\right)$ and net exports $\left(N E X_{T}\right)$. Tradable consumption data is obtained by deducting investment and net exports from the tradable sector's GDP, using real and nominal GDP data components. Tradable sector investments $\left(I_{T}\right)$ can be obtained from various data sources (e.g. EU KLEMS (The Conference Board, 2012, 2017), the World KLEMS and the CEIC database (CEIC Data, Inc.)). The consumption price $\left(P_{T}^{C}\right)$ is calculated by dividing nominal consumption by real consumption. As shown in Equation (1), demand for services is decomposed into consumption $\left(C_{S}\right)$ and investment $\left(I_{S}\right)$. The process for obtaining services data is the same as in the tradable sector.

The exogenous price ratio $(\Phi)$ is calculated by dividing the relative consumption deflator $\left(\frac{P_{S}^{C}}{P_{T}^{C}}\right)$ by the relative GDP deflator $\left(\frac{P_{S}}{P_{T}}\right)$. As mentioned earlier, $\frac{P_{S}}{P_{T}}$ is obtained from absolute relative price data. Because of data constraints, each sectoral deflator for $\frac{P_{S}^{C}}{P_{T}^{C}}$ uses each sector's price index. As a result, neither the ratio of these two relative prices nor the level of the exogenous price ratio $(\Phi)$ is especially meaningful; however, changing the ratio provides important information about sectoral transformation. The non-negative weight for services consumption $(\omega)$ is the average services consumption share for the entire analytical period. Except for India, elasticity of substitution $(\varepsilon)$ is set to equal 0.1 (complementarity), so that the analytical results can be compared to those of Dennis and İşcan [10]. For India, the value of $\varepsilon$ is set to 5.26 (a substitute), according to Verma [4]. Our model can explain actual consumption and employment services' shares for India, assuming that the two sectors' products are substitutes $\left[{ }^{4}\right]$.

\footnotetext{
${ }^{4}$ The elasticity of substitution $(\varepsilon)$ and the weight of services consumption $(\omega)$ can be obtained by regressing the logarithmic Equation (7). The same procedures were conducted by Verma [4]. However, this estimate is likely to produce a biased estimate of the coefficient for relative price $(\varepsilon)$ because of endogeneity bias. When estimating for sample countries without instrumental variables, we find that only the estimate for India yields
}

We calibrate the distortion parameter $\left(d_{i}\right)$ as follows. As mentioned above, $d_{i}=0$ is set assuming perfect factor mobility exists across the two sectors and that we factor relative price changes into relative capital deepening and relative TFP changes (referring to Equation (6)). The result, however, is disappointing, especially until the 1970s in Japan and the 1980s in South Korea, when these countries' per-capita incomes were relatively low. Analytically calculated relative labour share and relative capital stock differ greatly from the actual data. Based on the simulation's results, we assume that the degree of distortion depends on percapita income $(x)$, and we redefine $\frac{1+d_{S}}{1+d_{T}}$ in Equation (6), as follows:

$$
\frac{1+d_{S}}{1+d_{T}}=\exp (\alpha x+\beta)
$$

Where $\alpha$ takes on a negative value since the degree of the distortion diminishes with economic development. We calibrate values of $\alpha$ and $\beta$ to dissipate the difference between the simulated results and the real data about relative labour share and relative capital stock in Japan and Korea. The results are $\alpha=-0.0001$ and $\beta=0.4 .{ }^{5}$ Equation (13), 'implied distortion index', is applied to all sample countries. Finally, the first simulated variables, $A_{i}, k_{i}$ and $\theta_{i}$, which assume $d_{i}=0$, are recalculated from Equation (6).

We use datasets from 22 countries from which data are available, specifically: South Africa, China, India, Japan, South Korea, Malaysia, the Philippines, Taiwan, Thailand, Argentina, Brazil, Chile, Colombia, Costa Rica, Mexico, the U.S., Denmark, Spain, France,

a value of $\varepsilon$ above unity (a substitute), while some countries have negative $\varepsilon$ values. These negative values indicate that relative prices quantities for services' demand are positively correlated under endogeneity bias, and India's estimation of $\varepsilon$ above unity alone suffers little from the bias. On the other hand, as shown in Figure 2, in virtually all countries, the production factor (labour) shifts into sectors where productivity is relatively low (services), and nominal added value in the services sector increases (Figure-1). This indicates that elasticity of substitution generally takes on a value below one. As the result, we set elasticity of substitution uniformly for sample countries other than India at 0.1 .

\footnotetext{
${ }^{5}$ We take per-capita income data $(x)$ from The Groningen Growth and Development Centre's Penn World Tables, Version 9.0. Per-capita income is calculated by dividing expenditure-side real GDP at chained PPPs (in millions of 2011 USD) by population (in millions).
} 
the United Kingdom, Italy and the Netherlands. Eleven of these countries are OECD members.

Numerous data sources support these calculations. Relative sectoral prices and relative labour productivity are calculated using sectoral, nominal GDP, real GDP and employment data from The Groningen Growth and Development Centre's TenSector Database, covering 1950 to 2012. Actual data availability varies by country. The ten sectors are: Agriculture, Mining, Manufacturing, Utilities, Construction, Wholesale and Retail Trade, Transport Services, Business Services, Government Services and Personal Services. In accordance with World Development Indicators (the World Bank) and Inklaar and Timmer [11] which provides the data of absolute relative value-added prices, Agriculture, Mining, Manufacturing, Utilities and Construction are categorized as the tradable sector. Other sectors comprise the services sector $\left[{ }^{6}\right]$.

Macro-based, labour-share data, investment data and trade data are obtained from The Groningen Growth and Development Centre's Penn World Tables, Version 9.0 and UNCTAD STAT (The United Nations Conference on Trade and Development).

Finally, to ascertain the model's usefulness, we compare results between the model's analytically calculated variables and actual data. Key variables are relative labour share $\left(\frac{1-\theta_{T}}{1-\theta_{S}}\right)$, capital stock share of services (relative capital stock) $\left(\frac{K_{S}}{K}\right)$ and relative TFP $\left(\frac{A_{T}}{A_{S}}\right)$. Tekeuchi [9] shows that the first two variables can be replicated well by the above model.
${ }^{6}$ Inklaar and Timmer [11] provided data about absolute, relative 2005 value-added prices for 42 countries. Other countries' data (not provided by Inklaar and Timmer [11]) are obtained by estimation. Absolute, relative prices in the services sector, compared with those of the tradable sector, can be estimated linearly using logtransformed, per-capita income for sample countries.

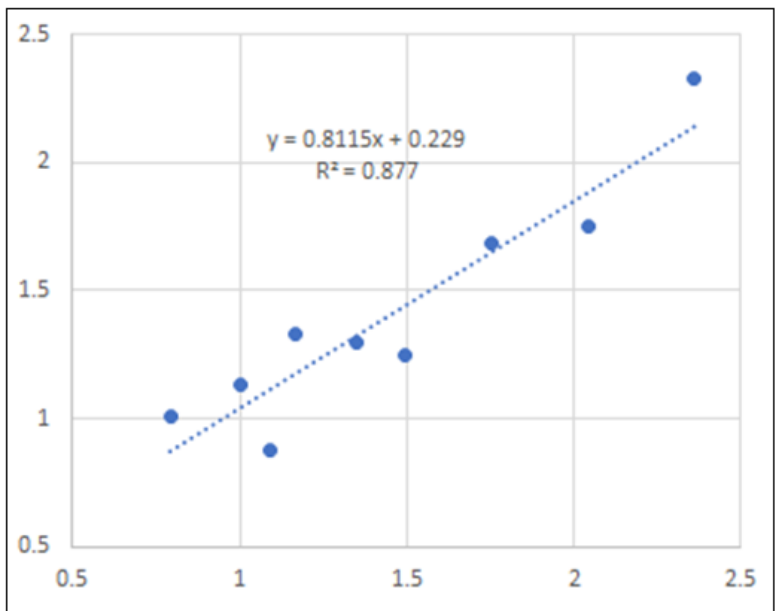

Fig-4: Rates of Change for the Model's Analytically Calculated TFP and Actual TFP Data of Nine Countries (the U.S., Denmark, Spain, France, the United Kingdom, Italy, the Netherlands, Japan and Korea). Calculated data is on the horizontal axis and actual data is on the vertical axis

Figure-4 compares calculated data from the model with actual data for the relative TFP of seven countries listed in EU KLEMS (2017 release), as well as Japan and South Korea. Sectoral TFP data from EU KLEMS and other sources do not indicate absolute TFP levels. As a result, differences in relative TFP levels between EU KLEMS's data and calculated data is not especially meaningful. Figure 4 indicates the relationship between gross change rates of calculated TFP (the horizontal axis) and those of actual TFP (the vertical axis) for the nine countries. As shown in the table, the model can replicate relative TFP changes. (Average change rates of actual and calculated relative TFP for nine countries are 1.406 and 1.450, respectively; therefore, an average difference test cannot be rejected). When taken together, the model, with a distortion factor, explains the actual data well in almost all countries.

\section{RESULTS}

Table- 1 shows the contribution of each of the four sources of structural change in terms of relative consumption (value-added) values across two sectors for some country groups (Equation (9)). ${ }^{7}$ To compare the impacts of these factors among different countries, the change rate of each factor is divided by the sum of the absolute values of the five change rates (including residuals) for the indicated periods. The right half of Table 1 shows the t-values of the test for average differences between the two indicated groups. We find significant differences in the factors' contribution between Latin America and other groups. In Latin America, the largest contribution comes from the relative capital-deepening factor, while the relative TFP factor is more significant in East Asia and OECD countries.

${ }^{7}$ The Decomposition results of structural transformation for 22 sample countries are shown in the Appendix. 
Differences in the contributions of relative capital-deepening factors among sample countries occur because the relative capital share $\left(\frac{\theta_{T}}{\theta_{S}}\right)$ changes differently. For the sample countries, Figure 4 indicates the relationship between the change rates of relative capital share $\left(\frac{\theta_{T}}{\theta_{S}}\right)$ (the horizontal axis, as a percentage) and the capital-deepening factor's contribution rates $\left(\left(\frac{1-\theta_{T}}{1-\theta_{S}}\right)^{1-\varepsilon}\left(\frac{k_{T}^{\theta_{T}}}{k_{S}^{\theta_{S}}}\right)^{1-\varepsilon}\right)$ (the vertical axis, as a percentage).

Table-1: Decomposition of Structural Transformation, Measured by Relative Consumption Values across Two Sectors

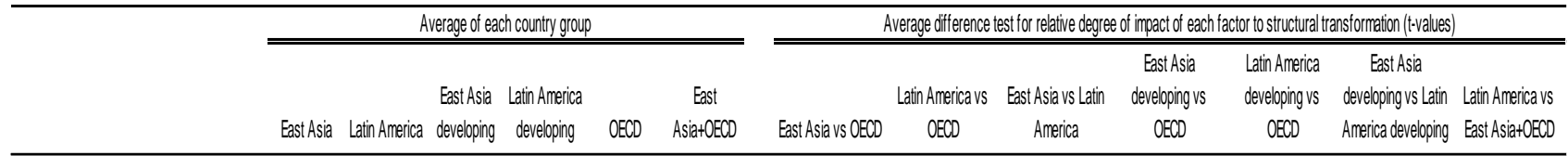

\begin{tabular}{lrrrrrr}
\hline Annual average rate of change $(\%)$ & & & & & & \\
Relative TFP & 1.80 & -1.14 & 1.27 & -0.87 & 0.91 & 1.35 \\
Relative capital deepening & -0.01 & 2.06 & -0.09 & 1.92 & 0.43 & 0.21 \\
Distortion & -1.23 & -0.74 & -1.01 & -0.77 & -0.58 & -0.91 \\
Exogenous price effect & 0.22 & -0.56 & 0.01 & -0.72 & 0.32 & 0.27
\end{tabular}

\begin{tabular}{|c|c|c|c|c|c|c|c|c|c|c|c|c|c|}
\hline Relative TFP & 22.71 & -18.80 & 14.09 & .13 .72 & 30.46 & 26.59 & 0.48 & 4.02 & $2.91 *$ & 0.75 & 3.18 * & 1.29 & 4.36 \\
\hline Relative capital deepening & 2.30 & 39.38 & 2.62 & 37.95 & 8.46 & 5.38 & 0.55 & 4.25 ttk & $4.06^{\text {tit }}$ & 0.37 & 3.90 & $2.41^{* *}$ & $5.75^{* * t+}$ \\
\hline Distortion & .16 .29 & -14.23 & -13.69 & .15 .35 & .15 .21 & .15 .75 & 0.35 & 0.33 & 0.82 & 0.54 & 0.04 & 0.62 & 0.68 \\
\hline Exogenous price effect & 2.37 & -5.40 & -0.07 & -6.09 & 7.72 & 5.05 & 0.76 & 1.39 & 1.07 & 1.07 & 1.10 & 0.54 & 1.37 \\
\hline
\end{tabular}

Notes: Country groups are categorised as follows: 'East Asia' includes China, Japan, South Korea, Malaysia, the Philippines, Taiwan and Thailand. 'East Asia developing' includes China, Malaysia, the Philippines and Thailand; 'LA' includes Argentina, Brazil, Chile, Colombia, Costa Rica and Mexico; 'LA developing' includes Argentina, Brazil, Colombia and Costa Rica and OECD (EuroAmerican) includes the U.S., Denmark, Spain, France, the United Kingdom, Italy and the Netherlands. $* * *=1 \%$ significance, $* *=$ $5 \%$ significance and $*=10 \%$ significance.

Table-2: Decomposition of Structural Transformation for Different Country Groups in Terms of Relative Employment across Two Sectors

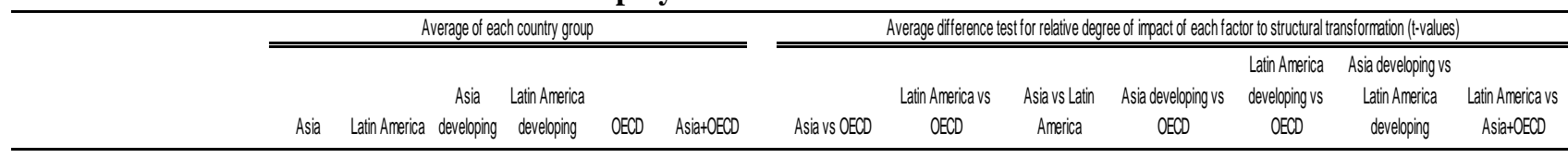

\begin{tabular}{lcccccc}
\hline Annual average rate of change $(\%)$ & & & & & & \\
Relative TFP & 1.80 & -1.14 & 1.27 & -0.87 & 1.08 & 1.44 \\
Relative capital deepening & -0.05 & 3.19 & -0.17 & 2.91 & 0.50 & 0.22 \\
Distortion & 0.12 & 0.08 & 0.11 & 0.09 & 0.07 & 0.09 \\
Exogenous price effect & -0.02 & 0.06 & 0.00 & 0.08 & -0.03 & -0.03 \\
Demand composition & 0.12 & 0.14 & 0.10 & 0.22 & 0.38 & 0.25
\end{tabular}

\begin{tabular}{|c|c|c|c|c|c|c|c|c|c|c|c|c|c|}
\hline Relative TFP & 27.61 & -18.95 & 13.36 & -14.18 & 25.49 & 26.55 & 0.13 & $4.00^{\mathrm{mot}}$ & $2.95 *$ & 0.58 & 3.12 ** & 1.32 & 4.36 \\
\hline Relative capital deepening & 2.21 & 60.36 & 2.52 & 57.64 & 7.53 & 4.87 & 0.33 & $5.78^{* *+}$ & $4.22 * * *$ & 0.21 & $5.55 \ldots$ & $2.47^{* *}$ & 6.84 \\
\hline Distortion & 2.01 & 1.58 & 1.59 & 1.72 & 1.48 & 1.74 & 1.23 & 0.32 & 1.13 & 0.30 & 0.67 & 0.33 & 0.59 \\
\hline Exogenous price effect & -0.38 & 0.88 & 0.04 & 1.10 & -0.80 & -0.59 & 0.54 & 1.38 & 1.20 & 1.13 & 1.11 & 0.67 & 1.38 \\
\hline Demand composition & 2.35 & 4.13 & 2.26 & 6.22 & 3.84 & 3.09 & 0.18 & 0.03 & 0.32 & 0.17 & 0.24 & 0.44 & 0.18 \\
\hline
\end{tabular}

Notes: Country groups are categorised as in Table $1 . * * *=1 \%$ significance, $* *=5 \%$ significance and $*=10 \%$ significance.

This figure shows that countries with lower rates of change in relative capital share also have lower capital-deepening factor contribution rates, which, in turn, lead to lower consumption share by services.
Circle and square dots with dark colours in the first quadrant of Figure-5, which depict Latin American countries, indicate a rapid increase in relative capital share. 


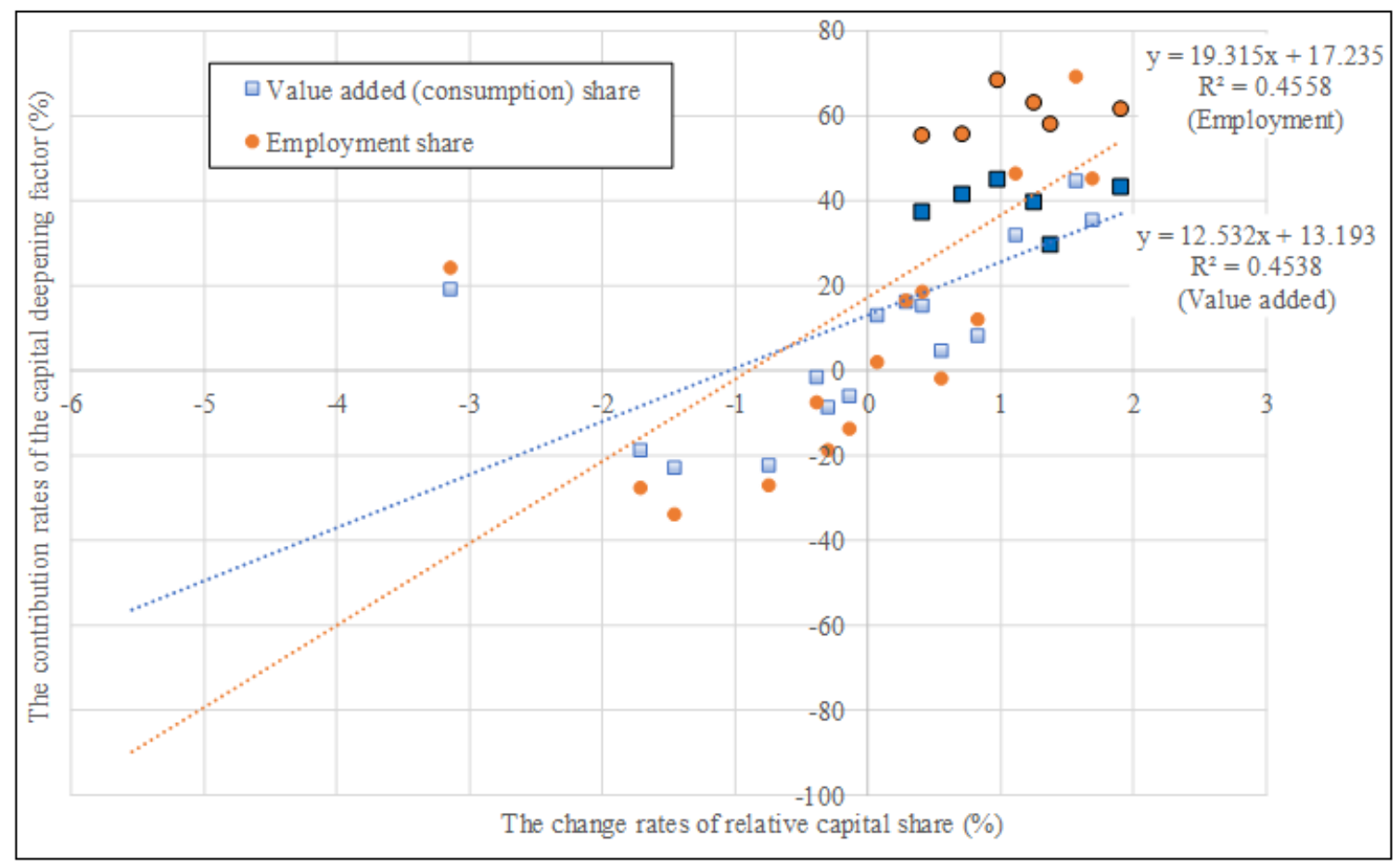

Fig-5: Change Rates of Relative Capital Share and Contribution Rates of the Capital-Deepening Factor, for Sample Countries Notes: Circles and square dots with dark colours depict Latin American countries

Figure-5 also points out that the impact of the increase in relative capital share on the contribution rates of the capital-deepening factor to sectoral changes is larger when services' share is treated as an employment share rather than as a value-added (consumption) share. This result is consistent with the observation in the Introduction that increases in services' share, seen as an employment share, are larger than those viewed as value-added shares. This difference, in fact, originates from distinctions between Equations (9) and (12). In many countries, relative capital share $\left(\frac{\theta_{T}}{\theta_{S}}\right)$ tends to increase when the tradable sector (especially the manufacturing sector) promotes capital deepening along with economic development. This decreases relative labour share $\left(\frac{1-\theta_{T}}{1-\theta_{S}}\right)$ and causes an increase in the relative capital-labour ratio $\left(\frac{k_{T}}{k_{S}}\right)$, from Equation (5). For the relative consumption shares, shown in Equation (9), $\left(\frac{1-\theta_{T}}{1-\theta_{S}}\right)^{1-\varepsilon}$ and $\left(\frac{k_{T}^{\theta_{T}}}{k_{S}^{\theta_{S}}}\right)^{1-\varepsilon}$ move in opposite directions, and changes in the capitaldeepening factor $\left(\left(\frac{1-\theta_{T}}{1-\theta_{S}}\right)^{1-\varepsilon}\left(\frac{k_{T}^{\theta_{T}}}{k_{S} \theta_{S}}\right)^{1-\varepsilon}\right)$ tend to be relatively small. By contrast, in Equation (12), $\left(\frac{1-\theta_{T}}{1-\theta_{S}}\right)^{-\varepsilon}$ and $\left(\frac{k_{T}^{\theta_{T}}}{k_{S}}\right)^{1-\varepsilon}$ move in the same direction, and changes in the capital-deepening factor $\left(\left(\frac{1-\theta_{T}}{1-\theta_{S}}\right)^{-\varepsilon}\left(\frac{k_{T}^{\theta_{T}}}{k_{S}^{\theta_{S}}}\right)^{1-\varepsilon}\right)$ tend to grow.
Relative capital-deepening and relative TFP, important factors in changing industrial structures, are also expected to affect economic development. The correlation coefficient between change rates of relative capital-deepening factor $\left(\left(\frac{1-\theta_{T}}{1-\theta_{S}}\right)^{1-\varepsilon}\left(\frac{k_{T}^{\theta_{T}}}{k_{S}^{\theta_{S}}}\right)^{1-\varepsilon}\right)$ and change rates of per-capita income for the sample countries is -0.304 . This indicates that a slow-paced capital deepening in the tradable sector, relative to the services sector, gradually increases the services sector's value-added share, resulting in relatively high economic growth. An increase in relative TFP also improves economic growth. The correlation coefficient for these variables is 0.507 (significant at $p=0.05$ ).

The relationships between capital-deepening and TFP factors, on the one hand, and economic development, on the other hand, are more significant in initial phases of development. As mentioned in Herrendolf et al., [1], services' value-added share to total GDP accelerates when per-capita income reaches a certain level. Therefore, we assume that any economy reaches this threshold when its log of per-capita income reaches approximately 8.5 (see Figure-1). Dividing the economic development process in each sample country into two phases and comparing how these relationships change, the correlation between the relative capitaldeepening factor's change rates and the change rates of per-capita income increases to -0.694 (significant at $p=0.05$ ) in the first phase and to -0.206 in the second phase. The correlation between the change rates of the relative TFP factor and the change rates of percapita income rises to 0.835 (significant at $p=0.01$ ) in the first phase and to 0.342 in the second phase. Slow- 
paced capital deepening contributes to relatively high economic growth, especially in early phases of development, because this kind of development strategy abets countries' comparative advantages. This strategy also seems to improve TFP.

Next, based on Equation (12), we turn to the factor decomposition results for employment share changes. In Table-2 (which corresponds to Table-1), as with consumption share changes, relative capitaldeepening and relative TFP factors play major roles in the higher relative services' employment share. One important, significant difference is the contribution rate of Latin America's relative capital-deepening factor, which has a larger influence here $(60.36 \%)$ than in value-added share decomposition $(39.38 \%)$. This result is consistent with the empirical finding, explained in the Introduction, that services' share rises more rapidly for Latin American countries when it is treated as an employment share rather than as a value-added share.

In Figure 1, and especially in Figure 2, where GDP per-capita (the income level) is on the horizontal axis and services' share is on the vertical axis, transformation trends are less pronounced for East Asia but are relatively steep for Latin America. The relative capital-deepening factor is lower in East Asian countries than in Latin American countries, leading to a gradual increase in the services sector's share. In East Asia and OECD countries, the relative TFP factor raises the share of services and also increases income. Overall, as shown in Figures 1 and 2, the transformation process appears to move more gradually in East Asia than in Latin America. On average, in Latin America, the relative TFP factor decreases income, while the capitaldeepening factor increases the services sector's share. Thus, the transformation process in Latin America appears to move more rapidly.

The factor decomposition analyses' results can be summarised as follows: (1) relative capitaldeepening and relative TFP factors play major roles in structural transformation, and changes in the respective shares of value-added and employment are almost the same. (2) In many countries with growing economies, increases in the proportion of services' employment is larger than that of services' added value. This is affected by changes in the relative capital share of the services sector versus the tradable sector. (3) The relationship between capital-deepening and TFP factors, on the one hand, and economic development, on the other hand, differs between East Asia and other regions. In Latin America, the services' share grows quickly, along with a rapid increase in capital share, which is out of line with countries' comparative advantages. Thus, growth rates stay relatively low, and TFP growth is stagnant.

\section{CONCLUSION}

This paper examines the structural transformation mechanisms in developing countries and assesses how they contribute to rising income levels. It focuses on two different patterns, a gradual shift to services coupled with high growth, and a rapid shift to services coupled with low growth. Previous studies have not determined how to divide these two distinctly different patterns. This paper focuses on the relationship between the tradable sector and the services sector as a structural transformation, because productivity in the services sector is relatively low, and a greater proportion of services in an economy will cause its growth rate to decline.

We find that, in line with their comparative advantages, developing economies in East Asia gradually increase the degree of capital intensification in the tradable sector. This constrains moving to a services-oriented industrial structure in the initial phases of economic development and increases income at the macro level. At the same time, relative TFP in the tradable sector versus the services sector has risen in East Asian developing countries. This boosts the relative prices of services, increases the services sector's share of nominal added value and contributes to a rise in income. Capital intensification and relative TFP gradually increase the services sector's share of nominal value-added and cause income gains. In other developing regions, such as Latin America, more rapid capital intensification growth in the tradable sector causes services to advance rapidly. Capital intensification in the tradable sector, which is out of line with certain countries' comparative advantages, has suppressed income growth.

An extant question is whether TFP or accumulation of production factors is the more important driver of economic growth in East Asia. This paper's analysis, which focuses on changes in labour and capital intensities, reveals that it is important for developing countries to raise capital intensity gradually, in line with their respective comparative advantages, especially during initial phases of development.

This article also focuses on differing patterns of structural transformation by simultaneously analysing value-added and employment shares. Different patterns may have important implications for income distribution. In many countries, the proportion of services' employment rises more rapidly than the proportion of services' added value. This is caused by the different way that capital intensification changes value-added and employment shares. 


\section{Appendix}

Decomposition of structural transformation in terms of the relative consumption values across two sectors

\begin{tabular}{|c|c|c|c|c|c|c|c|c|c|c|c|}
\hline & $\begin{array}{c}\text { South Africa } \\
1960-2011 \\
\end{array}$ & $\begin{array}{c}\text { China } \\
1980-2010 \\
\end{array}$ & $\begin{array}{c}\text { India } \\
1980-2007 \\
\end{array}$ & $\begin{array}{c}\text { Japan } \\
1953-2011 \\
\end{array}$ & $\begin{array}{c}\text { Korea } \\
1964-2010 \\
\end{array}$ & $\begin{array}{c}\text { Malaysia } \\
1975-2011 \\
\end{array}$ & $\begin{array}{l}\text { Philippines } \\
1972-2007 \\
\end{array}$ & $\begin{array}{c}\text { Taiw an } \\
1963-2011 \\
\end{array}$ & $\begin{array}{c}\text { Thailand } \\
1960-2011 \\
\end{array}$ & $\begin{array}{c}\text { Argentina } \\
\text { 1950-2011 } \\
\end{array}$ & $\begin{array}{c}\text { Brazil } \\
1990-2011 \\
\end{array}$ \\
\hline \multicolumn{12}{|c|}{ Annual average rate of change (\%) } \\
\hline Relative TFP & -1.91 & 3.11 & -8.10 & 2.22 & 3.99 & -1.47 & 1.66 & 4.73 & -1.67 & -1.08 & -1.37 \\
\hline Relative capital deepening & 2.10 & -0.91 & 6.56 & -0.08 & 0.44 & 1.43 & -0.60 & -2.87 & 2.53 & 1.67 & 2.65 \\
\hline Distortion & -0.41 & -1.09 & 2.60 & -1.44 & -2.12 & -1.23 & -0.46 & -1.36 & -0.93 & -0.84 & -1.19 \\
\hline Exogenous price effect & -0.30 & -0.08 & 1.58 & 0.28 & 1.17 & -0.07 & 0.20 & 0.53 & -0.52 & 0.20 & -3.40 \\
\hline residual & 1.87 & 5.09 & 1.61 & 2.24 & 1.69 & 3.27 & -0.30 & 3.01 & 0.04 & 0.69 & -0.33 \\
\hline Sectoral change & 1.36 & 6.12 & 4.23 & 3.21 & 5.16 & 1.93 & 0.49 & 4.04 & -0.54 & 0.64 & -3.64 \\
\hline \multicolumn{12}{|c|}{ Relative degree of impact of each factor to structural transformation (\%) } \\
\hline Relative TFP & -29.01 & 30.25 & -39.65 & 46.06 & 42.43 & -19.62 & 51.34 & 37.85 & -29.35 & -24.03 & -15.33 \\
\hline Relative capital deepening & 31.91 & -8.88 & 32.07 & -1.66 & 4.64 & 19.09 & -18.72 & -22.96 & 44.60 & 37.27 & 29.65 \\
\hline Distortion & -6.18 & -10.59 & 12.70 & -23.03 & -22.56 & -16.47 & -14.24 & -10.86 & -16.29 & -18.78 & -13.29 \\
\hline Exogenous price effect & -4.51 & -0.80 & 7.72 & 4.50 & 12.44 & -0.99 & 6.33 & 4.26 & -9.14 & 4.42 & -38.05 \\
\hline residual & 28.40 & 49.47 & 7.87 & 35.73 & 17.93 & 43.83 & -9.38 & 24.06 & 0.62 & 15.49 & -3.68 \\
\hline
\end{tabular}

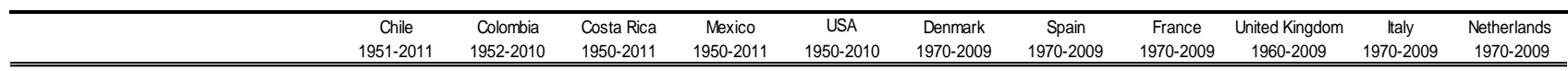

Annual average rate of change $(\%)$

\begin{tabular}{|c|c|c|c|c|c|c|c|c|c|c|c|}
\hline \\
\hline Relative TFP & -2.23 & -1.44 & 0.40 & -1.12 & 1.20 & -1.95 & 1.30 & 1.27 & 2.47 & 1.36 & 0.74 \\
\hline Relative capital deepening & 2.68 & 2.15 & 1.23 & 2.02 & -0.20 & 2.76 & 0.35 & 0.26 & -1.22 & 0.42 & 0.62 \\
\hline Distortion & -0.74 & -0.49 & -0.58 & -0.58 & -0.39 & -0.60 & -0.26 & -0.83 & -0.70 & -0.57 & -0.71 \\
\hline Exogenous price effect & -0.37 & 0.16 & 0.18 & -0.11 & -0.24 & 0.17 & -0.08 & 0.77 & -0.02 & -0.02 & 1.63 \\
\hline \multirow[t]{2}{*}{ residual } & 0.75 & 0.72 & 0.58 & 0.65 & 1.25 & 2.30 & 0.70 & 0.15 & 1.04 & -0.26 & 0.39 \\
\hline & u.uy & 1.11 & 1.80 & 0.85 & 1.62 & 2.68 & 2.26 & 2.45 & 2.21 & 1.50 & 3.39 \\
\hline \multicolumn{12}{|c|}{ Relative degree of impact of each factor to structural transformation (\%) } \\
\hline Relative TFP & -32.89 & -29.00 & 13.49 & -25.04 & 36.54 & -25.08 & 48.26 & 38.57 & 45.38 & 51.57 & 18.00 \\
\hline Relative capital deepening & 39.54 & 43.35 & 41.53 & 44.95 & -6.18 & 35.46 & 12.86 & 8.07 & -22.32 & 16.08 & 15.23 \\
\hline Distortion & -10.95 & -9.85 & -19.49 & -13.00 & -11.83 & -7.68 & -9.66 & -25.30 & -12.87 & -21.77 & -17.35 \\
\hline Exogenous price effect & -5.51 & 3.30 & 5.96 & -2.51 & -7.32 & 2.17 & -3.12 & 23.56 & -0.40 & -0.68 & 39.83 \\
\hline residual & 11.10 & 14.50 & 19.52 & 14.50 & 38.13 & 29.60 & 26.10 & 4.50 & 19.03 & -9.90 & 9.60 \\
\hline
\end{tabular}

Notes: Relative degree of impact of each factor to structural transformation (\%) is calculated by dividing the change rate of each factor by the sum of the absolute values of the five change rates (including residual) for the indicated periods. The bold text indicates factors with the largest and second largest degrees of contribution to structural transformation for each country.

Decomposition of structural transformation in terms of the relative employment across two sectors

\begin{tabular}{|c|c|c|c|c|c|c|c|c|c|c|c|}
\hline & $\begin{array}{c}\text { South Africa } \\
1960-2011 \\
\end{array}$ & $\begin{array}{c}\text { China } \\
1980-2010 \\
\end{array}$ & $\begin{array}{c}\text { India } \\
1980-2007 \\
\end{array}$ & $\begin{array}{c}\text { Japan } \\
\text { 1953-2011 } \\
\end{array}$ & $\begin{array}{c}\text { Korea } \\
1964-2010 \\
\end{array}$ & $\begin{array}{c}\text { Malaysia } \\
\text { 1975-2011 } \\
\end{array}$ & $\begin{array}{l}\text { Philippines } \\
\text { 1972-2007 } \\
\end{array}$ & $\begin{array}{c}\text { Taiw an } \\
\text { 1963-2011 } \\
\end{array}$ & $\begin{array}{c}\text { Thailand } \\
\text { 1960-2011 }\end{array}$ & $\begin{array}{c}\text { Argentina } \\
\text { 1950-2011 } \\
\end{array}$ & $\begin{array}{c}\text { Brazil } \\
\text { 1990-2011 } \\
\end{array}$ \\
\hline \multicolumn{12}{|c|}{ Annual average rate of change (\%) } \\
\hline Relative TFP & -1.91 & 3.11 & -8.10 & 2.22 & 3.99 & -1.47 & 1.66 & 4.73 & -1.67 & -1.08 & -1.37 \\
\hline Relative capital deepening & 3.05 & -1.28 & 5.49 & -0.25 & 0.71 & 1.38 & -1.41 & -4.15 & 4.63 & 2.85 & 3.79 \\
\hline Distortion & 0.05 & 0.12 & 3.20 & 0.12 & 0.17 & 0.14 & 0.05 & 0.15 & 0.10 & 0.09 & 0.13 \\
\hline Exogenous price effect & 0.03 & 0.01 & -3.83 & -0.03 & -0.13 & 0.01 & -0.02 & -0.06 & 0.06 & -0.02 & 0.38 \\
\hline Demand composition & 0.02 & 1.53 & -0.01 & 0.01 & 0.32 & -0.14 & -0.08 & -0.76 & -0.07 & -0.44 & 0.10 \\
\hline residual & 1.51 & 0.71 & 5.32 & 0.65 & -1.46 & 2.57 & 1.83 & 0.23 & -0.16 & 0.67 & -0.76 \\
\hline Sectoral change & 2.75 & 4.20 & 2.07 & 2.72 & 3.59 & 2.49 & 2.03 & 2.30 & 2.88 & 2.07 & 2.26 \\
\hline \multicolumn{12}{|c|}{ Relative degree of impact of each factor to structural transformation (\%) } \\
\hline Relative TFP & -29.05 & 46.02 & -31.22 & 67.58 & 58.90 & -25.75 & 32.84 & 38.62 & -24.91 & -20.94 & -20.97 \\
\hline Relative capital deepening & 46.43 & -18.98 & 21.14 & -7.59 & 10.43 & 24.21 & -27.86 & -33.91 & 69.15 & 55.37 & 58.03 \\
\hline Distortion & 0.69 & 1.79 & 12.34 & 3.61 & 2.49 & 2.40 & 1.01 & 1.23 & 1.54 & 1.82 & 2.02 \\
\hline Exogenous price effect & 0.50 & 0.14 & -14.75 & -0.95 & -1.92 & 0.14 & -0.45 & -0.48 & 0.86 & -0.43 & 5.78 \\
\hline Demand composition & 0.29 & 22.60 & -0.04 & 0.44 & 4.68 & -2.42 & -1.58 & -6.20 & -1.10 & -8.48 & 1.49 \\
\hline residual & 23.04 & 10.47 & 20.49 & 19.82 & -21.57 & 45.07 & 36.26 & 19.56 & -2.44 & 12.96 & -11.71 \\
\hline
\end{tabular}

\begin{tabular}{|c|c|c|c|c|c|c|c|c|c|c|c|}
\hline & $\begin{array}{c}\text { Chile } \\
\text { 1951-2011 } \\
\end{array}$ & $\begin{array}{c}\text { Colombia } \\
1952-2010 \\
\end{array}$ & $\begin{array}{l}\text { Costa Rica } \\
1950-2011 \\
\end{array}$ & $\begin{array}{c}\text { Mexico } \\
1950-2011 \\
\end{array}$ & $\begin{array}{c}\text { USA } \\
1950-2010 \\
\end{array}$ & $\begin{array}{c}\text { Denmark } \\
1970-2009 \\
\end{array}$ & $\begin{array}{c}\text { Spain } \\
1970-2009 \\
\end{array}$ & $\begin{array}{c}\text { France } \\
1970-2009 \\
\end{array}$ & $\begin{array}{c}\text { United Kingdom } \\
1960-2009 \\
\end{array}$ & $\begin{array}{c}\text { Italy } \\
1970-2009 \\
\end{array}$ & $\begin{array}{r}\text { Netherlands } \\
1970-2009 \\
\end{array}$ \\
\hline \multicolumn{12}{|c|}{ Annual average rate of change (\%) } \\
\hline Relative TFP & -2.23 & -1.44 & 0.40 & -1.12 & 1.33 & -1.95 & 2.35 & 1.27 & 2.47 & 1.36 & 0.74 \\
\hline Relative capital deepening & 4.28 & 3.24 & 1.78 & 3.19 & -0.42 & 3.65 & 0.18 & 0.41 & -1.68 & 0.58 & 0.81 \\
\hline Distortion & 0.08 & 0.05 & 0.06 & 0.06 & 0.04 & 0.07 & 0.04 & 0.09 & 0.08 & 0.06 & 0.08 \\
\hline Exogenous price effect & 0.04 & -0.02 & -0.02 & 0.01 & 0.03 & -0.02 & 0.01 & -0.09 & 0.00 & 0.00 & -0.18 \\
\hline Demand composition & -0.03 & 0.51 & 0.71 & 0.01 & 0.48 & -0.68 & 3.56 & -0.05 & 0.37 & -0.33 & -0.71 \\
\hline \multirow[t]{2}{*}{ residual } & -0.12 & -0.01 & -0.23 & 0.26 & 0.70 & 1.73 & -2.75 & 1.53 & 1.56 & 1.20 & 1.86 \\
\hline & 2.03 & 2.34 & 2.70 & 2.42 & 2.17 & 2.80 & 3.39 & 3.17 & 2.80 & 2.87 & 2.60 \\
\hline \multicolumn{12}{|c|}{ Relative degree of impact of each factor to structural transformation (\%) } \\
\hline Relative TFP & -32.88 & -27.29 & 12.47 & -24.07 & 44.04 & -24.10 & 26.39 & 36.90 & 40.07 & 38.28 & 16.87 \\
\hline Relative capital deepening & 63.19 & 61.61 & 55.55 & 68.39 & -13.93 & 45.08 & 1.98 & 11.93 & -27.28 & 16.42 & 18.47 \\
\hline Distortion & 1.22 & 1.03 & 2.00 & 1.39 & 1.48 & 0.82 & 0.49 & 2.69 & 1.26 & 1.80 & 1.81 \\
\hline Exogenous price effect & 0.61 & -0.35 & -0.61 & 0.27 & 1.09 & -0.23 & 0.10 & -2.50 & 0.04 & 0.06 & -4.15 \\
\hline Demand composition & -0.40 & 9.59 & 22.27 & 0.30 & 16.11 & -8.35 & 40.07 & -1.33 & 6.01 & -9.42 & -16.22 \\
\hline residual & -1.71 & -0.13 & -7.10 & 5.59 & 23.35 & 21.42 & -30.96 & 44.65 & 25.34 & 34.02 & 42.49 \\
\hline
\end{tabular}

Notes: Relative degree of impact of each factor to structural transformation (\%) is calculated by dividing the change rate of each facto by the sum of the absolute values of the five change rates (including residual) for the indicated periods. The bold text indicates factors with the largest and second largest degrees of contribution to structural transformation for each country. 


\section{REFERENCES}

1. Herendorf, B., Rogerson, R., \& Valentinyi, Á. (2014). Growth and structural transformation. In Chapter 6 of Handbook of Economic Growth Vol. 2, edited by Philippe Aghion and Steven N. Durlauf, Elsevier.

2. Krugman, P. (1994). The myth of Asia's miracle. Foreign Affairs, 73(6):62-78.

3. Jorgenson, D. W., \& Vu, K. M. (2009). Growth accounting within the international comparison program. The ICP Bulletin, 6(1):3-13.

4. Verma, R. (2012.) Can total factor productivity explain value-added growth in services? Journal of Development Economics, 99(1), 163-177.

5. Buera, F. J., \& Kaboski, J. P. (2009). Can traditional theories of structural change fit the data? Journal of the European Economic Association, 7(2-3):469-477.

6. [6] Kongsamut, P., Rebelo, S., \& Xie, D. (2001). Beyond balanced growth. Review of Economic Studies, 68(4):869-882.
7. Ngai, L. R., \& Pissarides, C. A. (2007). Structural change in a multisector model of growth. The American Economic Review, 97(1):429-443.

8. Takeuchi, F. (2019). Structural transformation and income inequality, revisited. Review of Socio Economic Perspectives, 4(2):17-35.

9. Takeuchi, F. (2019). The declining labor income shares revisited: Intersectoral production linkages in global value chains, In Chapter 2 of Globalization. Edited by George Yungchih Wang, Intech Open.

10. Dennis, B. N., \& İşcan, T. B. (2009). Engel versus Baumol: Accounting for structural change using two centuries of U.S. data. Explorations in Economic History, 46(2):186-202.

11. Inklaar, R., \& Timmer, M. (2014). The relative price of services. Review of Income and Wealth, 60(4):727-746. 